\title{
GAYA KEPEMIMPINAN YANG EFEKTIF DALAM MENINGKATKAN KESELAMATAN PASIEN
}

\author{
Sri Mulyatiningsih ${ }^{1}$, Usman Sasyari ${ }^{2}$ \\ ${ }^{1}$ Dosen Manajemen Keperawatan PSIK-FIKes Universitas Borobudur \\ ${ }^{2}$ Dosen Manajemen Keperawatan PSIK-FIKes Universitas Muhammadiyah Tasikmalaya \\ Email: srimulyatiningsih519719@ gmail.com ${ }^{1}$, usman.sasyari@umtas.ac.id ${ }^{2}$
}

\begin{abstract}
Abstrak
Keselamatan pasien merupakan hak pasien, pasien berhak memperoleh keamanan dan keselamatan dirinya selama dalam perawatan di rumah sakit dan pelayanan kesehatan harus mendahulukan keselamatan nyawa pasien. Keselamatan pasien menjadi prioritas untuk layanan kesehatan di seluruh dunia. Insiden keselamatan pasien menimbulkan dampak buruk dan kerugian berupa kematian, gangguan fungsi tubuh atau kecacatan, kerugian finansial dan menurunkan kepercayaan masyarakat terhadap pelayanan rumah sakit. Salah satu faktor untuk meningkatkan keselamatan pasien adalah kepemimpinan. Kepemimpinan dengan gaya kepemimpinan yang efektif dapat meningkatkan keselamatan pasien. Tujuan penelitian ini adalah memberikan gambaran gaya kepemimpinan yang efektif untuk meningkatkan keselamatan pasien. Design penelitian ini yaitu study literatur tentang gaya kepemimpinan yang efektif untuk meningkatkan keselamatan pasien. Hasil peneltian menunjukan bahwa gaya kepemimpinan yang efektif untuk meningkatkan keselamatan pasien adalah gaya kepemimpinan transformasional. Kesimpulan Gaya kepemimpinan transformasional berkontribusi positif untuk iklim keselamatan.
\end{abstract}

Kata Kunci: kepemimpinan, gaya kepemimpinan, kepemimpinan transformasional, keselamatan pasien

\section{Abstract}

Patient safety is a patient's rights, the patient has the rights to get their own safety and security while in hospital care and health services must be put the safety of the patient's life first. Patient safety is a priority for healthcare services around the world. Patient safety incidents cause adverse effects and losses in the form of death, impaired body function / disability, financial losses and reduce public confidence in hospital services. One of the factors to improve patient safety is leadership. Effective leadership style can improve patient safety. The purpose of this study is to describe an effective leadership style to improve patient safety. The design of this study is a literature study on effective leadership styles to improve patient safety. The results of this study indicate that an effective leadership style to improve patient safety is a transformational leadership style. Conclusion The transformational leadership style contributes positively to the safety climate.

Keywords: Leadership, leadership style, transformational leadership patient safety

\section{Pendahuluan}

Keselamatan pasien merupakan hak pasien, pasien berhak memperoleh keamanan dan keselamatan dirinya selama dalam perawatan di rumah sakit (Permenkes no. 14 tahun 2018). Sesuai dengan UU No 36/2009 tentang kesehatan pasal 53 (3) menyatakan bahwa pelaksanaan pelayanan kesehatan harus mendahulukan keselamatan nyawa pasien. Keselamatan pasien telah menjadi prioritas untuk layanan kesehatan di seluruh dunia (Cosway, Stevens, \& Panesar, 2012). Rumah sakit merupakan salah satu organisasi yang berisiko tinggi terhadap terjadinya insiden keselamatan selain industri penerbangan, nuklir, dan kimia (Reason, 2008). Insiden disebabkan oleh kesalahan prosedur. Kesalahan umumnya disebabkan oleh kegagalan sistem di mana individu tersebut bekerja (Reason, 2008). 
Insiden keselamatan pasien menimbulkan dampak buruk dan kerugian berupa kematian, gangguan fungsi tubuh/ kecacatan, kerugian keuangan dan menurunkan kepercayaan masyarakat terhadap pelayanan rumah sakit. Angka insiden keselamatan pasien dikatakan sebagai fenomena gunung es, angka insiden yang ada hanya sebagian kecil dari kemungkinan angka kejadian yang sebenarnya. USA memberikan kontribusi tingginya angka kejadian kematian pada pasien rawat inap setiap tahunnya 44.000 98.000 (Cosway, Stevens, \& Panesar, 2012; Reason, 2008), di Inggris diperkirakan sekitar 850.000 kejadian buruk terjadi pertahunnya disebabkan oleh kesalahan dalam identifikasi pasien, dengan kerugian satu milyar pound sterling pertahun dan di Australia $8 \%$ dari pasien yang dirawat mengalami peristiwa yang merugikan dengan kerugian sebesar 4,7 milyar dolar Australia pertahun (Murphy \& Kay, 2004; White, 2012).

Faktor-faktor yang menyebabkan insiden keselamatan pasien adalah keterampilan klinis dan non klinis perawat dalam melaksanakan keselamatan pasien. Insiden keselamatan pasien diperkirakan 70-80\% disebabkan oleh keterampilan non klinis meliputi komunikasi, kerjasama tim, kepemimpinan dan followership, kesadaran terhadap situasi yang terjadi, dan pengambilan keputusan (Flin, O'Connor \& Crichton, 2008; Yule, Flin, Peterson, brown \& Maran, 2006; Westli, Johnsen, Eid, Rasten \& Brattebo, 2010). Kepemimpinan yang tidak baik merupakan salah satu faktor yang menyebabkan insiden keselamatan pasien.

Kepemimpinan untuk meningkatkan perilaku perawat dalam melaksanakan keselamatan pasien yaitu kepemimpinan yang baik. Kepemimpinan adalah faktor yang paling penting untuk mencapai prestasi besar (Kostik, Sahin, Demir, \& Kavumcubasi, 2005) diperkuat oleh penelitian Pollard, Avella, Hockin, \& Samson, (2008) bahwa kepemimpinan penting dalam opersional organisasi dan kesuksesan tergantung pada efektifitas pemimpin tanpa kepemimpinan organisasi tidak dapat eksis karena tidak ada perintah, kebijakan, standar, dan proses untuk mencapai tujuan organisasi.

Pengaruh kepemimpinan sangat penting sebagaimana disampaikan oleh Casida \& Parker (2011) bahwa kinerja yang unggul dan efektifitas organisasi adalah tampilan yang konsisiten dari perilaku kepemimpinan transformasional. Diperkuat dengan hasil penelitian Lawton, Carruthers, Gardner, Wright, \& McEachan (2012) diidentifikasi sepuluh kegagalan laten yang mendukung kesalahan pengobatan salah satunya adalah pengawasan dan kepemimpinan. White (2012) juga menyoroti dalam studi kasusnya bahwa kerja tim akan mengalami kerusakan dan tidak terkoordinasi bila tidak ada kepemimpinan yang jelas dalam mengendalikan situasi sehingga perawat melakukan tugas sesuai kemauan dan inisiatifnya sendiri dan komunikasi tidak efisien ke seluruh tim dan terdapat ketidaksesuaian tugas.

Menurut Permenkes (2011) kepemimpinan berperan dalam meningkatkan keselamatan pasien yaitu mendorong dan menjamin implementasi program keselamatan pasien, menjamin berlangsungnya program proaktif untuk identifikasi risiko keselamatan pasien dan program menekan atau mengurangi insiden, mendorong dan menumbuhkan komunikasi dan koordinasi, mengalokasikan sumber daya yang adekuat, mengukur dan mengkaji efektifitas kontribusinya dalam meningkatkan kinerja rumah sakit dan keselamatan. Kepemimpinan yang baik ditunjukkan pulaoleh komunikasi yang baik, 
mentoring, dan kemampuan untuk maju (Luthra,A., \& Dahiya, R., 2015).

Pemimpin keperawatan mulai dari pimpinan terendah yaitu ketua tim, kepala ruangan, kepala instalasi rawat inap/jalan sampai kepala bidang keperawatan harus mempunyai keterampilan kepemimpinan dan merupakan sesuatu yang dipersyaratkan atau kompetensi yang harus dipenuhi untuk menduduki jabatan tersebut. Meningkatkan keselamatan pasien dalam organisasi perawatan kesehatan membutuhkan kepemimpinan yang efektif di semua tingkatan (Boamah \& Clarke, 2018).

Perawat sebagai manajer asuhan dan manajer pelayanan harus memenuhi kompetensi tersebut, sebagaimana disampaikan oleh Krugman \& Smith (2003) bahwa kepemimpinan sangat penting dalam pengelolaan pasien sehingga mendapatkan hasil yang optimal. Manajer perawat yang menggunakan kekuasaan dan menggabungkannya dengan kepemimpinan, fungsi manajemen dan kompetensi akan meningkatkan efektifitas (Garsia \& Barbara, 2009).

Kepemimpinan dengan gaya kepemimpinan yang seperti apa yang efektif untuk meningkatkan keselamatan pasien. Dalam jurnal ini akan melakukan penelusuran terkait gaya kepemimpinan yang efektif untuk meningkatkan keselamatan pasien.

\section{Tinjauan Teoritis}

Keselamatan Pasien merupakan suatu sistem di rumahsakit yang menjamin bahwa asuhan asuhan pasien lebih aman. Sistem tersebut meliputi: Kajian risiko, Identifikasi dan pengelolaan hal yang berhubungan dengan risiko pasien, Pelaporan dan analisis insiden, Kemampuan belajar dari insiden dan tindak lanjut serta implementasi solusi untuk meminimalkan timbulnya risiko. Sistem tersebut diharapkan dapat mencegah terjadinya cedera yang disebabkan oleh kesalahan dalam melakukan atau tidak atau tidak melakukan tindakan yang seharusnya dilakukan.

Tujuan keselamatan pasien adalah terciptanya budaya keselamatan pasien di di rumahsakit, meningkatnya akuntabilitas, menurunnya kejadian tidak diharapkan (KTD), terlaksananya program programprogram pencegahan sehingga tidak terjadi pengulangan kejadian yang tidak diharapkan.

Tujuh Langkah menuju keselamatan pasien adalah bangun kesadaran akan nilai keselamatan pasien dimulai dari menciptakan kepemimpinan dan budaya yang terbuka dan adil, Pimpin dan dukung staf dengan cara membangun komitmen dan fokus yang kuat dan jelas tentang keselamatan pasien, integrasikan aktivitas pengelolaan risiko dengan mengembangkan sistem dan proses pengelolaan risiko serta lakukan identifikasi dan kajian hal yang potensial bermasalah, kembangkan sistem pelaporan dengan cara memastikan staf agar dengan mudah dapat melaporkan kejadian/insiden, serta rumahsakit mengatur pelaporan kepada KKPRS, libatkan dan berkomunikasi dengan pasien dengan cara mengembangkan cara-cara komunikasi yang terbuka dengan pasienm belajar dan berbagi pengalaman tentang keselamatan pasien untuk mendorong staf melakukan analisis akar masalah untuk belajar bagaimana dan mengapa kejadian itu timbul, Cegah cedera melalui implementasi sistem keselamatan pasien dengan menggunakan infromasi yang ada tentang kejadian/masalah untuk melakukan perubahan sistem pelayanan.

Gaya kepemimpinan dan kecenderungannya, yang harus diperhatikan adalah bagaimana seorang manajer keperawatan harus dapat memiliki inisiatif, mampu mengembangkan dan memahami perubahan-perubahan yang terjadi, yang 
berhubungan langsung maupun tidak langsung terhadap peningkatan keselamatan pasien. Perubahan pola kepemimpinan terjadi karena kondisi yang terus bergerak dinamis, struktur kelembagaan yang terus mengalami perubahan secara sistemik dan budaya masyarakat yang berkembang dalam kebutuhan keamanan dan keselamatan pasien. Kepemimpinan merupakan suatu kemampuan yang hanya dapat diukur melalui hasilnya yaitu tercapainya tingkat keselamatan pasien yang tinggi.

Kepemimpinan dengan gaya kepemimpinan transformational berkontribusi positif terhadap keselamatan pasien (Boamah \& Clarke, 2018).. Kepemimpinan transformasional muncul dalam kondisi yang senantiasa berubah dan perubahan tersebut semakin dinamis. Sebagaimana dinamisnya upaya yang dilakukan untuk meningkatkan keselamatan pasien yang disesuaikan dengan tuntutan masyarakat dan perkembangan ilmu pengetahuan dan teknologi,

Menurut Marquis \& Houston, (2012) Kepemimpinan transformasional adalah kepemimpinan yang loyal, memiliki visi dan mampu memberdayakan orang lain dengan visinya. menyamakan visi baru dan memberikan energi yang diperlukan untuk menggerakan unit organisasi menuju tujuan ogranisasi dalam hal ini keselamatan pasien. Hal ini seiring dengan upaya-upaya untuk meningkatkan keselamatan pasien yang dihadapkan pada perkembangan ilmu pengetahuan dan teknologi yang memerlukan adanya manajer keperawatan dengan kepemimpinan yang memiliki inovasi dan visioner. Menurut Yuki (2006) kepemimpinan yang visioner yang mampu menatap jauh ke depan karena kondisi yang terjadi dan akan berlangsung semakin rumit, mampu memindahkan kondisi masa kini menjadi tantangan dalam mempimpin di masa depan (prediktif) berdasarkan situasi yang dihadapi saat ini, mampu mempersiapkan secara sistematik untuk menjadi penerus dalam kepemimpinannya adalah kepemimpinan transformasional. Kepemimpinan, budaya keselamatan pasien, dan iklim yang kondusif untuk inovasi dalam perawatan pasien diperlukan untuk memajukan hasil keselamatan pasien yang positif (Younger, S., 2019).

\section{Metode}

Metode yang digunakan yaitu penelusuran jurnal gaya kepemimpinan yang efektif untuk meningkatkan keselamatan pasien, mencakup design, studi, sampel, dan hasil penelitian jurnal yang ditelusuri.

\section{Hasil}

Penelitian mengenai Efektifitas kepemimpinan transformational pada kepuasan kerja dan keselamatan pasien (Boamah \& Clarke, 2018). Hasil penelitian ini didapatkan kepemimpinan transformasional memiliki pengaruh positif yang kuat pada pemberdayaan tempat kerja, yang meningkatkan kepuasan kerja perawat dan menurunkan jumlah kejadian yang merugikan pasien. Design penelitian pemodelan persamaan structural (structural equation modeling) dengan tingkat signifikansi 0,05 . Metode yang digunakan survei cross sectional secara random. Penelitian ini menggunakan 378 responden perawat yang bekerja pada ruang perawatan akut di Ontaria.

Penelitian mengenai Gaya Kepemimpinan dan implikasi keselamatan pasien bagi manajer keperawatan (Merrill \& Collette, 2015). Hasil peneltian ini didapatkan Gaya kepemimpinan transformasional berkontribusi positif untuk iklim keselamatan, sedangkan gaya kepemimpinan laissez-faire terbukti berkontribusi negatif pada sosialisasi unit dan budaya keselamatan pasien. Design 
penelitian deskriptif korelatif, dengan jumlah sampel 466 responden perawat di 41 departemen keperawatan pada 9 rumah sakit. Analisis yang digunakan bivariat dan regresi untuk menentukan seberapa baik gaya kepemimpinan memprediksi iklim keselamatan, dengan tingkat signifikansi 0,05 .

Penelitian mengenai Gaya kepemimpinan dan persepsi perawat terhadap keselamatan pasien (Younger,S., 2019) Hasil penelitian ini didapatkan kepemimpinan transformasional memiliki hubungan yang signifikan secara statistik dengan persepsi perawat tentang keselamatan pasien $(\beta=$ $0,75, \quad \mathrm{p}<0,001)$ sedangkan hubungan kepemimpinan transaksional dengan persepsi keselamatan pasien tidak signifikan $(\beta=0,18)$. Variabel diukur menggunakan tiga instrumen survei yang tervalidasi dan andal: Kuesioner Kepemimpinan Multifaktor (MLQ Form 5X), Tim Climate Inventory-short (TCI), Survei Agency for Healthcare Research and Quality (AHRQ) Hospital on Patient Safety Culture. Sampel adalah semua staf perawat $(\mathrm{N}=952)$ disurvei melalui email, yang kembali sebanyak 210 sampel dan yang memenuhi kriteria inklusi 157 sampel. Karakteristik responden mayoritas perempuan $(136 ; 86,6 \%)$, rentang usia antara 20 tahun sampai 60 dan mayoritas antara 20 sampai 34 tahun (86; $54,8 \%$ ), pendidikan mayoritas sarjana muda keperawatan $(103 ; 65,6 \%)$, masa kerja mayoritas 1 sampai 5 tahun $(98 ; 62,4 \%)$, responden mayoritas bekerja pada shift pagi $(121 ; 77,1 \%)$. Analisis yang digunakan regresi linier berganda dengan tingkat signifikansi 0,05 .

\section{Pembahasan}

Manajer keperawatan harus mempunyai kompetensi kepemimpinan yang efektif sesuai dengan perkembangan dan tuntutan tugas untuk meningkatkan keselamatan pasien. Manajer perawatan harus menggunakan metode manajemen modern untuk mengatasi tantangan yang dihadapi dalam sistem perawatan dan budaya keselamatan. (Farokhzadian, Nayeri \& Borhani, 2018). Upaya peningkatan keselamatan pasien merupakan proses dinamis yang terus berubah, dan itu tergantung pada keadaan dan perkembangan ilmu pengetahuan dan teknologi terkait keselamatan pasien, yang didukung oleh gaya kepemimpinan yang sesuai dengan kondisi tersebut.

Gaya kepemimpinan dan kecenderungannya, yang harus diperhatikan adalah bagaimana seorang manajer keperawatan harus dapat memiliki inisiatif, mampu mengembangkan dan memahami perubahan-perubahan yang terjadi, yang berhubungan langsung maupun tidak langsung terhadap peningkatan keselamatan pasien. Perubahan pola kepemimpinan terjadi karena kondisi yang terus bergerak dinamis, struktur kelembagaan yang terus mengalami perubahan secara sistemik dan budaya masyarakat yang berkembang dalam kebutuhan keamanan dan keselamatan pasien. Kepemimpinan merupakan suatu kemampuan yang hanya dapat diukur melalui hasilnya yaitu tercapainya tingkat keselamatan pasien yang tinggi.

Kepemimpinan dengan gaya kepemimpinan transformational berkontribusi positif terhadap keselamatan pasien (Boamah \& Clarke, 2018).. Kepemimpinan transformasional muncul dalam kondisi yang senantiasa berubah dan perubahan tersebut semakin dinamis. Sebagaimana dinamisnya upaya yang dilakukan untuk meningkatkan keselamatan pasien yang disesuaikan dengan tuntutan masyarakat dan perkembangan ilmu pengetahuan dan teknologi, 
Menurut Marquis \& Houston, (2012) Kepemimpinan transformasional adalah kepemimpinan yang loyal, memiliki visi dan mampu memberdayakan orang lain dengan visinya. menyamakan visi baru dan memberikan energi yang diperlukan untuk menggerakan unit organisasi menuju tujuan ogranisasi dalam hal ini keselamatan pasien. Hal ini seiring dengan upaya-upaya untuk meningkatkan keselamatan pasien yang dihadapkan pada perkembangan ilmu pengetahuan dan teknologi yang memerlukan adanya manajer keperawatan dengan kepemimpinan yang memiliki inovasi dan visioner. Menurut Yuki (2006) kepemimpinan yang visioner yang mampu menatap jauh ke depan karena kondisi yang terjadi dan akan berlangsung semakin rumit, mampu memindahkan kondisi masa kini menjadi tantangan dalam mempimpin di masa depan (prediktif) berdasarkan situasi yang dihadapi saat ini, mampu mempersiapkan secara sistematik untuk menjadi penerus dalam kepemimpinannya adalah kepemimpinan transformasional. Kepemimpinan, budaya keselamatan pasien, dan iklim yang kondusif untuk inovasi dalam perawatan pasien diperlukan untuk memajukan hasil keselamatan pasien yang positif (Younger, S., 2019).

Manajer yang menunjukkan kepemimpinan transformasional di tempat kerja memiliki potensi yang lebih besar untuk menciptakan lingkungan yang mendukung praktik keperawatan profesional yang mempromosikan perawatan pasien berkualitas tinggi. Kepemimpinan transformasional secara tidak langsung mempengaruhi kepuasan kerja perawat dan menurunkan prevalensi yang merugikan bagi pasien. (Boamah \& Clarke, 2018). Kepemimpinan transformasional dalam keperawatan berkaitan dengan perawatan pasien yang lebih baik (Fischer, 2016).
Pentingnya

kepemimpinan transformasional dalam menciptakan lingkungan praktik yang memberdayakan yang mendorong perawatan berkualitas tinggi. Dalam merencanakan strategi keselamatan, manajer harus menunjukkan perilaku kepemimpinan transformasional dengan memodifikasi lingkungan kerja untuk menciptakan pertahanan yang lebih baik untuk menghindari kejadian yang tidak diinginkan (Boamah, S., 2018). Seorang yang memiliki gaya kepemimpinan transformasional adalah yang mampu memberikan dorongan pada orang lain pada saat membutuhkan (Northouse, 2007).

Kepemimpinan dengan gaya transformasional memberikan kontribusi unik pada literatur dan pemahaman tentang peran kepemimpinan transformasional dalam mengoptimalkan lingkungan praktik keperawatan dan hasil pasien. Oleh karena itu memiliki implikasi penting untuk pengembangan profesional manajer perawat dan desain kurikulum kepemimpinan (Higgins,Elisabeth, 2015). Organisasi dan lingkungan berperan penting dalam mengembangkan dan mendukung terbentuknya keterampilan kepemimpinan tramsformasional (Marquis \& Houston, 2012).

Kepemimpinan transaksional tidak signifikan terhadap persepsi keselamatan pasien (Younger, S., 2019). Kepemimpinan transaksional berfokus pada pelaksanaan tugas keseharian. Meskipun kepemimpinan transformasional merupakan gaya kepemimpinan yang ideal namun Marquis \& Houston (2012) menjelaskan bahwa pemimpin transformasioanl juga harus melakukan peran manajerial tradisional (transaksional), kedua karakteristik tersebut harus ada pada pada diri individu yang sama dalam derajat yang berbeda. Pemimpin transformasional akan gagal tanpa keterampilan manajemen transaksional. 
Kepemimpinan dengan gaya kepemimpinan laissez-faire terbukti berkontribusi negatif terhadap keselamatan pasien (Merrill \& Collette, 2015). Kepemimpinan laissez-faire merupakan pemimpin dengan tidak memberikan pimpinan, membiarkan staf untuk berbuat sekehendak sendiri-sendiri, tidak ada pemberian petunjuk/saran/arahan, tidak ada pengawasan dan kontrol kegiatan dari stafnya. Kekuasaan dan tanggung jawab simpangsiur sehingga tidak mudah dikendalikan. Kepemimpinan laisses-faire berkorelasi positif dengan konflik peran, ambiguitas peran dan konflik dengan rekan kerja, kepemimpinan laisses-faire adalah perilaku yang merusak (Skogstad, A., Einarsen, S., Torsheim. T., at all, 2007).

Kepemimpinan transformasional, transaksional, dan pasif akan memprediksi kepribadian kolektif dan kepribadian kolektif akan secara signifikan terkait dengan kinerja kolektif (Hofmann, D.A. \& Jones, L.M. 2005). Gaya kepemimpinan berpengaruh terhadap kinerja dalam meningkatkan upaya keselamatan pasien.

Peningkatan keselamatan pasien melalui kepemimpinan harus ada komitmen. Komitmen organisasi dan kepatuhan manajer rumah sakit terhadap kepemimpinan dapat meningkatkan kinerja perawat dalam hal keselamatan pasien (Lotfi, Shoorideh, Mohtashami \& Nasiri, 2018). Organisasi dan lingkungan berperan penting dalam mengembangkan dan mendukung keterampilan kepemimpinan transformasional dan transaksional pada stafnya. Kepemimpinan transformasioanl dengan baik akan mampu meningkatkan komitmen organisasi. Kepemimpinan transformasional dengan visinya memberdayakan stafnya untuk menggali kesamaan dan rasa keterikatan (Marquis \& Houston, 2012).

\section{Kesimpulan}

Berdasarkan hasil dari beberapa studi literatur di atas menunjukan bahwa gaya kepemimpinan transformational berkontribusi positif terhadap keselamatan pasien. Kepemimpinan transaksional tidak sinifikan terhadap persepsi keselamatan pasien, wakaupun kepemimpinan transformasional merupakan gaya kepemimpinan yang ideal tetapi pemimpin transformasioanl juga harus melakukan peran manajerial tradisional (transaksional), kedua karakteristik tersebut harus ada pada pada diri individu yang sama dalam derajat yang berbeda. Pemimpin transformasional akan gagal tanpa keterampilan manajemen transaksional. Sedangkan gaya kepemimpinan laissez-faire terbukti berkontribusi negatif, dari gaya kepemimpinan lain yaitu gaya kepemimpinan demokratis dan otoriter.

Gaya kepemimpinan dari manajer keperawatan mempengaruhi hasil baik tidaknya terhadap keselamatan pasien. Gaya kepemimpinan dapat memprediksi kepribadian organisasi dan signifikan terhadap budaya keselamatan organisasi. Oleh karena itu, penting untuk memberi tahu eksekutif perawat mengenai dampak gaya kepemimpinan pada keselamatan pasien, dan gaya kepemimpinan yang efektif untuk meningkatkan keselamatan pasien. Pemimpin keperawatan harus berkonsentrasi pada pengembangan keterampilan kepemimpinan yang efektif dan mengurangi gaya kepemimpinan negatif. Perawat pada semua tingkatan diharapkan menerapkan kepemimpinan dalam lingkungan praktik keperawatan.

Rekomendasi yang dapat diberikan yaitu rumah sakit dapat meningkatkan keselamatan pasien secara efektif dengan meningkatkan peran dan fungsi 
kepemimpinan yang efektif yaitu kepemimpinan transformasional.

\section{Daftar Referensi}

Boamah, S., (2018). To patient care quality: The role of transformational leadership and workplace empowerment. Canadian journal of nursing research 50 (1), 9-19.

Boamah, S.A., Laschinger, H.K.S., Wong, C., Clarke, S. (2018). Effect of transformational leadership on job satisfaction and patient safety outcomes. Nursing outlook 66 (2), 180189.

Casida, J., \& Parker, J. (2011). Staff nurse perceptions of nurse manager leadership styles and outcomes. Journal of Nursing Managemen. Vol.19/No.19.

Cosway, B., Stevens, A.C., \& Panesar, S. (2012). Clinical leadership: A role for students? British Journal of Hospital Medicine. Vol.73/No.1.

Fischer, S.A., (2016). Transformational leadership in nursing a concept analysis. Journal of advanced nursing 72 (11), 2644-2653.

Flin, R., O'Connor, \& Crichton, M. (2008). Safety at the sharp end: A guide to non-technical skills. Ashgate Publishing.

Garsia, S.B., Barbara, L.P, \& Heater A.C. (2009). Toward a framework for an inclusive model of social justice leadership preparation.

Hofmann, D.A. \& Jones, L.M., (2005). Leadership, collective personality, and performance. Journal of Applied Psychologi. Vo..90, No.3, 509-522.

Kementerian Kesehatan RI, (2009). Undang-Undang No. 36 tentang Kesehatan.

Kementerian Kesehatan RI, (2011). Peraturan menteri kesehatan nomor 169/MENKES/PER/VIII/2011 tentang keselamatan pasien rumah sakit.

Kostik, Z., Sahin, B., Demir, C., Kavuncubasi, S. (2005). An evaluation of the leadership attitudes of managers in turkish armed forces' hospitals. Military Medicine. Vol.170/No.3.

Krugman, M., \& Smith, V. (2003). Chargenurse leadership development and evaluation. JONA. Vol.33/No.5.

Lawton, R., Carruthers, S., Gardner, P., Wright, J., \& McEachan, R.C. (2012) Identifying the latent failures underpinning medication administration errors: An exploratory study. Health Research and Educational Trust. Vol.47/No.2.
Loffi, Z., Shoorideh, F.A., Mohtashami, J., Nasiri, M., (2018). Relationship between ethical leadership and organizational commitment of nurses with perception of patient safety culture. Journal of nursing management 26 (6), 726-734.

Luthra, A. \& Dahiya, R., (2015). Effective leadership is all about communicating effectively: connecting leadership and communication, IJMBS Vol.5.

Mabesau. (2012). Kepemimpinan TNI Angkatan Udara. Jakarta: Mabesau Cilangkap.

Marquis, B.L., \& Huston, C.J. (2012). Leadership roles \& management functions in nursing: Theory \& application. Philadelphia: Wolters Kluwer Health/Lippincott Williams \& Wilkins.

Merril, Collete, K., (2015). Leadership style and patient safety implications for nurse managers. JONA volume 45-issue 6-p319-324.

Murphy, M.F. \& Kay, J.D.S. (2004). Patient identification: problems and potential solutions. Blackwell Publishing Ltd. Vox Sanguinis. Vol.87/No.2.

Northouse, Peter.G., (2007). Leadership Theory and Practise. California: Sage Publications, Inc.

Pollard, B.M., Avella, J., Hockin, R., \& Samsom, L. (2008). The effects of leadership style on the job performance of nurses. UMI Microform

Reason, J. (2008). The human contribution: Unsafe acts, accidents and heroic recoveries. Ashgate Publishing, Farnham.

Robbins, S.P. (2006). Perilaku organisasi. Indonesia: PT Indeks Kelompok Gramedia.

Ring, L., Fairchild, R. M., (2013). Leadership and patient safety: A review of the literature. https://doi.org/10.1016/S21558256(15)30164-2.

Skogstad, A., Einarsen, S., Torsheim. T., at all, (2007). The destructiveness of laisses faire leadership behavior. Journal of occupational health psychology 12 (1).80.

Storr, J., Topley, K., \& Privett, S., (2005). The ward nurse's role in infection control. Nursing Standard. Vol.19/No.41.

Swanburg, R.C. (2002). Pengantar kepemimpinan \& manajemen keperawatan: Untuk perawat klinis. Jakarta: EGC.

Westli, H.K., Johnsen, B.H., Eid, J., Rasten, I., \& Brattebø, G. (2010). Teamwork skills, shared mental models, and performance in simulated trauma teams: an independent group design. Scandinavian Journal of Trauma, 
Resuscitation and Emergency Medicine. Vol.18/No.47.

White, N. (2012). Understanding the role of nontechnical skills in patient safety. Nursing Standard. Vol.26/No.26.

Wong, C. A., Cummings, G.G., Ducharme, L., (2013). The relationship between nursing leadership and patient outcomes: a systematic review update. Journal of nursing management 21 (5), 709-724.

Younger, S. , (2019). Exploring the roleof climate for innovationon the relationship between leadership style and nurses' perception of patient safety.

Yule, S., Flin, R., Paterson, Brown, S., Maran, N. (2006) Non-technical skills for surgeons in the operating room: a review of the literature. Surgery. Vol.139/No.2.

Yuki,Gary., (2006). Leadership in Organizations. New Jersey: Pearson Prentice Hall.

Mulyatiningsih, Gaya Kepemimpinan Yang Efektif Dalam Meningkatkan Keselamatan Pasien I 35 